Uluslararası Mühendislik

\title{
Çözündürme ve Yaşlandırma İşleminin Al-7Si-4Zn-3Cu Alaşımının Sürtünme ve Aşınma Özelliklerine Etkisi
}

\section{Effect of Age Hardening on the Wear Behaviour of the Al-7Si-4Zn-3Cu Alloy}

\author{
Yasin Alemda $\breve{\mathbf{g}}^{\mathrm{iD}}$, Murat $\operatorname{Beder}^{2}$ iD \\ ${ }^{I}$ Department of Mechanical Engineering, Karadeniz Technical University, Trabzon-TURKEY \\ ${ }^{2}$ Department of Mechanical Engineering, Gümüşhane University, Gümüşhane-TURKEY
}

Başvuru/Received: 25/02/2019

Kabul/Accepted: $15 / 05 / 2019$

Son Versiyon/Final Version: 30/06/2019

\begin{abstract}
$\ddot{O} z$
Bu çalışmada, çözündürme ve su verme işleminden sonra T6 ve T7 koşullarında yaşlandırma işlemine tabi tutulan Al-7Si-4Zn$3 \mathrm{Cu}$ alaşımının sürtünme ve aşınma özellikleri incelenmiştir. Elde edilen sonuçlar söz konusu alaşımın dökülmüş durumu ile karşılaştırılmıştır. Bu işlemlerden sonra alaşımın sürtünme katsayısının artığı ancak aşınma kaybının azaldığı gözlenmiştir. Özellikle T6 ve T7 ısıl işlemleri uygulanmış alaşımın yüksek yük ve kayma hızlarında dökülmüş durumuna göre oldukça üstün aşınma direnci sergilediği görülmüsşür. Diğer taraftan T6 1sıl işleminin T7 1sıl işlemine göre alaşımın aşınma direnci üzerinde daha etkili olduğu belirlenmiştir. Elde edilen bu sonuçlar hem dökülmüş hem de ısıl işlem görmüş durumdaki alaşımın sertlik ve mukavemetleri ile bu alaşımda ortaya çıkan aşınma mekanizmalarına dayandırılarak açıklanmıştır.
\end{abstract}

\section{Anahtar Kelimeler}

“Al-Si alaşımları, mikro yapı, yaşlandırma, sürtünme ve aşınma"

\begin{abstract}
In this study, the friction and wear properties of the $\mathrm{Al}-7 \mathrm{Si}-4 \mathrm{Zn}-3 \mathrm{Cu}$ alloy aged $\mathrm{T} 6$ and $\mathrm{T} 7$ conditions after its solutionizing and quenching treatment were investigated. The results obtained from heat treated alloy were compared to its as-cast state. The friction coefficient of the alloy increased but its volume loss decreased after the T6 and T7 heat treatments. It was especially observed that the alloy aged T6 and T7 conditions exhibited higher wear resistance than its as-cast state at high load and sliding speed. On the other hand, T6 heat treatment was determined to be more powerful effect than the T7 to improve the wear resistance of the alloy. The results obtained were explained in terms of the hardness and strength of the alloy with its wear mechanism at both heat treated and as-cast states.
\end{abstract}

Key Words

"Al-Si alloys, microstructure, quench aging, mechanical properties, friction and wear", 


\section{Giriş}

Alüminyum-silisyum alaşımları özgül mukavemetinin (mukavemet/yoğunluk) ve aşınma direncinin yüksek olması, döküme ve işlenmeye elverişli olması, yüksek korozyon direncine ve termal iletkenliğe sahip olması gibi bazı üstün özelliklere sahiptir(Bai \& Biswas, 1987; Clarke \& Sarkar, 1979; Jasim \& Dwarakadasa, 1987; Sarkar, 1975; Sarkar \& Clarke, 1980; Torabian, Pathak, \& Tiwari, 1994). Bu özelliklerin söz konusu alaşımların içerdiği silisyum oranına bağlı olduğu bilinmektedir (Alemdag \& Beder, 2014; El-Salam, El-Khalek, Nada, Wahab, \& Zahran, 2010; Nikanorov et al., 2005; Sarkar \& Clarke, 1980).Silisyum oranı arttıkça bu alaşımların sertliğinin sürekli arttığı çekme dayanımlarının ise yaklaşık \%12 Si oranında en yüksek değerine ulaştıktan sonra bir düşüş sergilediği belirlenmiştir(Bai \& Biswas, 1987; Jasim \& Dwarakadasa, 1987; Sarkar \& Clarke, 1980; Torabian et al., 1994). Diğer taraftan Al-Si alaşımların aşınma direncinin artan silisyum oranı ile arttığı, özellikle aşırı yük ve hızlarda ötektik üstü alaşımların gerek ötektik gerekse ötektik altı alaşımlardan daha üstün aşınma davranışı ortaya koyduğu görülmüştür (Dwivedi, 2010; Ye, 2003). Ancak ötektik üstü alaşımların içyapılarında bulunun sert ve gevrek iri silisyum parçacıklarının hem bu alaşımların işlenmesinde kullanılan kesici takımların aşınmasına hem de eş çalıştığı yüzeylerde abrazyona yol açtığı tespit edilmiştir(Alemdag \& Beder, 2014; Alemdag \& Savaskan, 2008; Cui, Schulz, Matthaei-Schulz, \& Zoch, 2009; Prasad, 1997; Savaskan \& Aydiner, 2004; Savaskan \& Bican, 2005). Bu durumun ötektik üstü alaşımların kullanımını sınırlayan önemli bir sorun olduğu belirlenmiş̧ir. Bu nedenle Al-Si esaslı alaşım grubu içerisinde ötektik altı Al-7Si ve ötektik Al-12Si esaslı alaşımların içten yanmalı motorlara ait bazı parçaların üretiminde ve kaymalı yatak yapımında daha yaygın kullanıldığı göze çarpmaktadır.

İkili Al-Si alaşımlarının mekanik ve tribolojik özelliklerinin pek çok uygulama için yeterli olmadığı bilinmektedir(Chen \& Thomson, 2010; Eshaghi, Ghasemi, \& Rassizadehghani, 2011; Raghavan, 2007; Savaskan, Hekimoglu, \& Purcek, 2004; Tiryakioglu, 2008; Zedan, Samuel, Samuel, \& Doty, 2010). Bu özelliklerin iyileştirilmesinde alaşımlama ve 1sıl işlemin en uygun ve kolay uygulanabilir yöntemler olduğu görülmüştür (Anasyida, Daud, \& Ghazali, 2010; Cho, Hockey, Lawn, \& Bennison, 1989; Fatahalla, Hafiz, \& Abdulkhalek, 1999; Kori, Murty, \& Chakraborty, 2000; Mohamed, Samuel, Samuel, \& Doty, 2009; Nogita et al., 2010; Xu, Yang, Wang, \& Jiang, 2007). Bu nedenle Al-Si alaşımlarına bakır, demir, magnezyum, mangan, nikel, kurşun ve çinko gibi alaşım elementleri katılmış, elde edilen bazı alaşımlara ise normalizasyon, çözündürme ve yaşlandırma gibi ısıl işlemler uygulanmıştır(Chen \& Thomson, 2010; Eshaghi et al., 2011; Raghavan, 2007; Savaskan \& Aydiner, 2004; Savaskan et al., 2004; Tiryakioglu, 2008; Zedan et al., 2010). Alaşım elementleri arasında magnezyum, bakır ve çinko elementlerinin, isıl işlemler içerisinde ise çözündürme ve yaşlandırma 1sıl işleminin söz konusu alaşımların özelliklerini iyileştirmede çok daha etkili olduğu görülmüştür(Alemdag \& Beder, 2014; Birol, 2008; Cho et al., 1989; Kori et al., 2000; Nogita et al., 2010). Alemdağ ve Beder(2014) tarafından yapılan bir çalışmada çinko ve bakırın Al-7Si esaslı alaşımın mekanik ve aşınma özellikleri üzerindeki etkisi sistematik olarak incelenmiş, bu çalışmanın sonucunda üçlü $\mathrm{Al}-7 \mathrm{Si}-4 \mathrm{Zn}$ ve dörtlü $\mathrm{Al}-7 \mathrm{Si}-4 \mathrm{Zn}-3 \mathrm{Cu}$ alaşımları geliştirilmiştir (Alemdag \& Beder, 2014). Diğer taraftan dörtlü Al-7Si-4Zn-3Cu alaşımının üçlü Al-7Si-4Zn alaşımına göre daha üstün mekanik ve tribolojik özellikler sergilediği belirlenmiştir (Alemdag \& Beder, 2014). Bu durumun bakırın düşük oranlarda da olsa $\alpha$-Al fazı içerisindeki çözünürlüğünden ve bakırca zengin $\mathrm{CuAl}_{2}(\theta)$ fazının oluşumundan kaynaklandığı belirlenmiştir (Chen \& Thomson, 2010; Eshaghi et al., 2011; Raghavan, 2007; Savaskan \& Aydiner, 2004; Savaskan et al., 2004; Tiryakioglu, 2008; Zedan et al., 2010). Ancak bu alaşımın çözündürme ve yaşlandırma uygulanmış durumundaki aşınma davranışı henüz belirlenmemiştir. Bu nedenle bu çalışmada çözündürme ve yaşlandırma 1sıl işleminin söz konusu alaşımın sürtünme ve aşınma özelliklerine etkisi incelenmiş̧ir. Bu kapsamda çözündürme ve su verme işlemin ardından yaşlandırma işlemine tabi tutulan alaşımın yaşlandırılmış (T6) ve aşırı yaşlandırılmış (T7) durumundaki özellikleri döküm durumu ile karşılaştırılıp bu işlemlerin söz konusu alaşımın sürtünme ve aşınma davranışına etkisi belirlenmeye çalışılmıştır.

\section{Gereç ve yöntemler}

\subsection{Alaşım Üretimi, ısıl işlemi ve içyapısı}

Bu çalışma için kullanılan Al-7Si-4Zn-3Cu alaşımı kokil kalıba döküm yöntemi ile üretildi. Alaşımın üretiminde ticari saflıkta $\mathrm{Al}$ (\%99,7), yüksek saflıkta $\mathrm{Zn}(\% 99,9)$, Al-50Cu ve Al-12Si alaşımları kullanıldı. Bu malzemeler bir elektrikli firın içerisine $700^{\circ} \mathrm{C}$ sıcaklıkta ergitildikten sonra 5 dakika süreyle karıştırıldı ve ardından $690^{\circ} \mathrm{C}$ 'den oda sıcaklığında tutulan orta karbonlu çelikten imal edilmiş Ø57 mm x Ø72 mm x $180 \mathrm{~mm}$ boyutlarındaki konik kalıba dökülerek katılaştırıldı. Katılaşma tamamlandıktan sonra alaşım kalıptan çıkarıldı ve kimyasal bileşimi spektral analiz yöntemi kullanılarak belirlendi. Bu analiz sonucunda alaşımın kimyasal bileşiminde $\% 85,2 \mathrm{Al}, \% 7,3 \mathrm{Si}, \% 4,3 \mathrm{Zn}$ ve $\% 3,2 \mathrm{Cu}$ bulunduğu tespit edildi. Söz konusu alaşımdan talaşl1 imalat yöntemi ile $10 \mathrm{~mm}$ x $10 \mathrm{~mm}$ x $20 \mathrm{~mm}$ boyutunda numuneler hazırlandı. Bu numuneler $450{ }^{\circ} \mathrm{C}$ sıcaklıkta 36 saat çözündürme işlemine tabii tutulduktan sonra suda soğutuldu ve $150{ }^{\circ} \mathrm{C}$ sıcaklıkta 10 saat süreyle yapay yaşlandırıldı. Bu süreç zarfinda çeşitli zaman aralıklarında numunelerin sertlikleri ölçüldü ve alaşımın sertliğinin yaşlandırma süresine göre değiş̧imini gösteren eğri elde edildi, Şekil 1. Bu eğriden yararlanarak T6 ve T7 1sıl işlemleri için yaşlandırma süresi sırasıyla 30 dakika ve 5 saat olarak belirlendi.

Metalografik incelemeler için hem dökülmüş hem de 1 sıl işlem görmüş alaşımdan alınan numuneler soğuk kalıplama, taşlama ve parlatma işlemlerinden oluşan standart metalografi yöntemiyle hazırlandı. Bu numuneler nitrik asit (\% 6 HN03 +\% 94 alkol) çözeltisi içerisinde dağlandı. Dağlama işleminin ardından numunelerin içyapıları optik mikroskopta incelenerek (OM) fotoğrafları çekildi. 


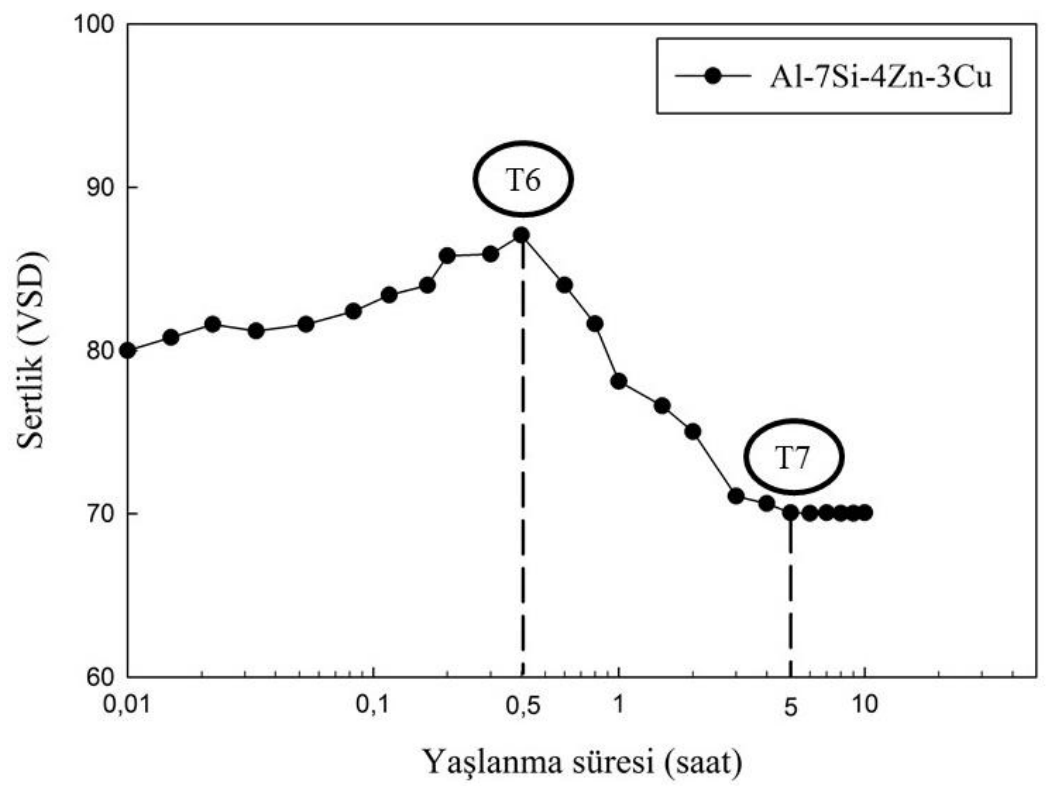

Şekil 1.Al-7Si-4Zn-3Cu alaşımının sertliğinin yaşlandırma süresine göre değişimini gösteren eğri

\subsection{Sertlik ve çekme deneyleri}

Dökülmüş ve $1 s 1$ işlem görmüş durumdaki alaşımın sertliği 50 gf büyüklüğünde bir yük kullanılarak Vickers sertlik ölçme yöntemi ile ölçüldü. Alaşımın çekme dayanımının belirlenmesinde tel erozyon yöntemi ile 2,5 mm x 5,6 mm x $20 \mathrm{~mm}$ boyutlarında üretilen yassı biçimde numuneler kullanıldı ve bu numuneler oda sıcaklığında $5 \times 10^{-4} \mathrm{~s}^{-1}$ deformasyon hızında çekme deneyine tabi tutuldu. Sertlik ve çekme deneyleri için en az beş ölçüm yapıldı ve bu ölçümlerin ortalaması alınarak söz konusu değerler belirlendi.

\subsection{Sürtünme ve aşınma deneyleri}

Alaşımların sürtünme ve aşınma deneyleri ASTM: G99 standartlarına uygun olarak tasarlanmış bilye-disk esaslı bir deney düzeneğinde gerçekleştirildi. Bu deney düzeneğinin genel görünümü ile test bölgesinin ayrıntısı Şekil 2'de şematik olarak gösterilmiştir. Sürtünme ve aşınma deneyleri için dökülmüş ve 1 sıl işlem görmüş durumdaki alaşımdan $\varnothing 24 \mathrm{~mm} \times 7 \mathrm{~mm}$ boyutlarında numuneler hazırlandı. Bu numunelerin yüzeyleri otomatik taşlama ve parlatma makinasında taşlandı ve ardından da parlatıldı. Bu işlemlerden sonra numunelerin yüzey pürüzlülüğ̈̈ $0,15 \pm 0,05 \mu \mathrm{m}$ olarak ölçüldü. Söz konusu numuneler için aşındırıcı yüzey olarak $6 \mathrm{~mm}$ çapında $100 \mathrm{Cr} 6$ çelik bilye kullanıldı.

Sürtünme ve aşınma deneylerinden önce numuneler ultrasonik bir temizleyicide temizlendi ve kütleleri $\pm 0,01 \mathrm{mg}$ hassasiyete sahip bir terazi ile ölçüldü. Bu işlem aşınma deneyinden sonra da tekrarlandı ve ölçülen kütle kaybı alaşımın yoğunluğuna bölünerek hacim kaybına dönüştürüldü. Sürtünme ve aşınma deneyleri $0,16 \mathrm{~ms}^{-1}$ 'lik kayma hızında ve farklı yüklerde $(2,5-12,5 \mathrm{~N})$ ve $5 \mathrm{~N}$ 'luk sabit bir yükte ve farklı kayma hızlarında $\left(0,08-0,22 \mathrm{~ms}^{-1}\right) 1000 \mathrm{~m}^{\prime}$ lik yola karşılık gelen kayma mesafesinde yapıldı. Her bir koşul için sürtünme kuvveti bir sensör vasıtasıyla ölçüldü ve bu değerler bir yazılım ile bilgisayar ortamına aktarıldı. Ölçülen sürtünme kuvveti normal yüke bölünerek sürtünme katsayısına dönüştürüldü ve bu değerin alınan yola göre değişimlerini gösteren eğriler elde edildi. Sürtünme katsayısının kararlı değişim sergilediği bölgedeki ortalama değerleri alınarak farklı yük ve kayma hızlarındaki alaşıma ait ortalama sürtünme katsayısı değerleri belirlendi.

Alaşımın dökülmüş ve 1 sıl işlem görmüş durumundaki etkin aşınma mekanizmasını belirlemek için aşınma deneylerinden sonra bunlara ait numunelerin yüzeyleri bir taramalı elektron mikroskobu (SEM) ile incelendi ve fotoğrafları çekildi. 


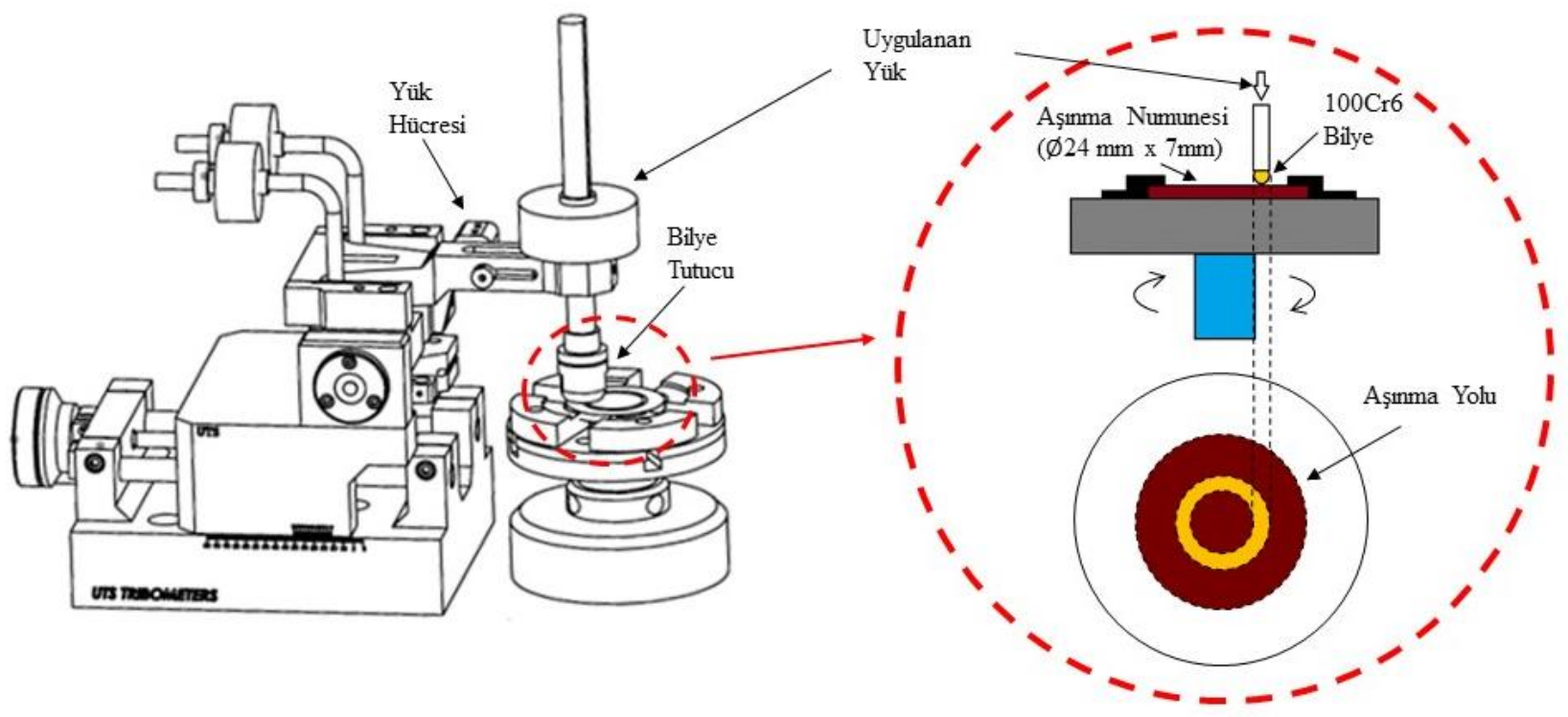

Şekil 2. Bilye-disk esaslı aşınma düzeneğinin ve test bölgesinin şematik gösterimi.

\section{Bulgular ve tartışma}

\subsection{Yapısal incelemelerden elde edilen bulgular}

Alaşımın döküm ve ısıl işlem görmüş durumundaki içyapısını gösteren OM fotoğrafları Şekil 3 (a-c) verilmiştir. Dökülmüş durumdaki alaşımın içyapısının $\alpha$-Al dendritleri, lamel biçimindeki $\alpha$-Al-Si ötektik karışımı, çok az miktarda birincil silisyum kristalleri ve bakırca zengin $\mathrm{CuAl}_{2}(\theta)$ fazından oluştuğu görülmüştür, Şekil 3 (a). Bu durum söz konusu alaşımın katılaşma davranışına dayandırılarak açıklanabilir. Ötektik altı olan bu alaşım, katılaşmaya başladığında ilk önce dendrit biçimindeki $\alpha$-Al taneleri oluşur ve bu taneler sürekli sıvıdan atom çekerek büyürler. Geriye kalan sıvının kimyasal bileşimi ötektik dönüşüm için gerekli bileşime ulaştı̆ında ötektik dönüşüm meydana gelir ve bunun sonucunda $\alpha$-Al ve Si kristallerinden oluşan lamel biçimindeki faz karışımı meydana gelir. Ancak çinkonun tamamının ve bakırın ise yaklaşık \%1,5 oranında alüminyum içerisinde çözündüğü geriye kalan bakırın ise alüminyumla reaksiyona girerek $\theta$ kristallerini oluşturduğu görülmüştür. Bu durum ötektik dönüşümün \%12 Si oranından daha düşük silisyum oranların da meydana gelmesine yol açmış olabilir. Nitekim alaşımlarında gözlenen birincil $\mathrm{Si}$ kristallerinin $\mathrm{Al}-\mathrm{Si}$ faz diyagramındaki ötektik noktanınsola doğru kaymasından dolayı oluştuğu düşünülmektedir. T6 ve T7 ısıl işlemleri sonucunda alaşımın dendritik yapısının nispeten ortadan kalktığı gözlenmiştir, Şekil 3 $(b, c) . \mathrm{Bu}$ durum çözündürme işlemi sonucunda elde edilen $\alpha$ - $\mathrm{Al}$ matrisinin hızlı soğutulması neticesinde dendritik formunu kaybetmesinden kaynaklanmıs olabilir.

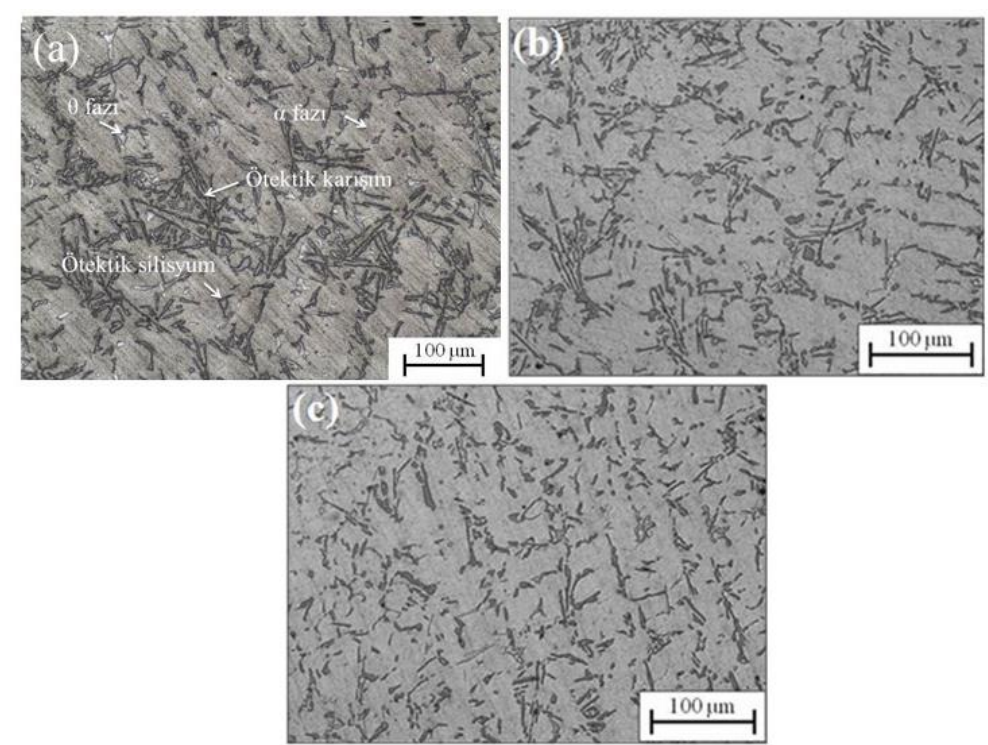

Şekil .3 Al-7Si-4Zn-3Cu alaşımının (a)dökülmüş (b) T6 ve (c) T7 ısıl işlem görmüş durumundaki iç yapısını gösteren OM fotoğrafları 


\subsection{Sertlik ve Çekme Deneylerinden Elde Edilen Bulgular}

Dökülmüş ve 1 ssıl işlem görmüş durumdaki alaşımın sertliği, akma ve çekme dayanımları ile kopma uzaması değerleri Tablo l'de verilmiştir. Bu tabloda görüldüğü gibi alaşımın sertliği T6 1sıl işlemi sonunda artmış, T7 1sıl işleminden sonra ise azalmıştır. Diğer taraftan hem T6 hem de T7 ssıl işlemi sonucunda alaşımın akma ve çekme dayanımı ile kopma uzaması değerlerinin artığ belirlenmiştir. Bu sonuçlar söz konusu alaşımın yaşlanma davranışına dayandırılarak açıklanabilir (Chen \& Thomson, 2010; Eshaghi et al., 2011; Raghavan, 2007; Savaskan \& Aydiner, 2004; Savaskan et al., 2004; Tiryakioglu, 2008; Zedan et al., 2010). Çözündürme işlemi uygulanan alaşımda bakırın $\alpha$-Al matrisi içerisinde çözündüğü ancak silisyum parçacıklarının bu işlemden etkilenmediği görülmüştür. Su verme işleminden sonra elde edilen aşırı doymuş katı çözeltinin yaşlandırılması sonucunda $\theta$ fazının tekrar oluştuğu belirlenmiştir. Bu fazın $\alpha$-Al matrisinden ayrışması sırasında ortaya çıkan bağdaşıklık gerilmeleri $\alpha$-Al matrisinin kafes yapısını çarpıtmış olabilir. Bu durum dislokasyon hareketlerini zorlaştırarak veya engelleyerek alaşımın sertlik ve mukavemetinin artmasına yol açmış olabilir. Ancak aşırı yaşlandırma döneminde bağdaşıklık durumunun ortadan kalkması ile birlikte $\alpha$-Al matrisindeki gerilmeler azalmaya başlar. Bu aşamada alaşımın sertliği azalarak belirli bir yaşlandırma süresinden sonra kararlı haline ulaşır. Sertlikteki düşüşe rağmen alaşımın akma ve çekme dayanımında belirlenen artış $\theta$ fazının dislokosyonların hareketini engellemesi sonucunda meydana gelmiş olabilir.

Tablo 1.Dökülmüş, T6 ve T7 1s1l işlemleri görmüş alaşımın mekanik özellikleri

\begin{tabular}{lcccc}
\hline \multicolumn{1}{c}{ Alaşım } & $\begin{array}{c}\text { Sertlik } \\
(\boldsymbol{V S D})\end{array}$ & $\begin{array}{c}\text { Çekme dayanımı } \\
(\boldsymbol{M P a})\end{array}$ & $\begin{array}{c}\text { Akma dayanımı } \\
(\boldsymbol{M P a})\end{array}$ & $\begin{array}{c}\text { Kopma uzaması } \\
(\boldsymbol{\%})\end{array}$ \\
\hline Al-7Si-4Zn-3Cu-Dökülmüş & 81 & 156 & 110 & 1,9 \\
Al-7Si-4Zn-3Cu-T6 & 87 & 214 & 141 & 2,7 \\
Al-7Si-4Zn-3Cu-T7 & 71 & 225 & 155 & 2,3
\end{tabular}

\subsection{Sürtünme ve Aşınma Deneylerinden Elde Edilen Bulgular}

Al-7 $\mathrm{Si}-4 \mathrm{Zn}-3 \mathrm{Cu}$ alaşımının hem döküm hem de 1 sıl işlem görmüş durumundaki sürtünme katsayısının uygulanan yük ve kayma hızına göre değişimlerini gösteren eğriler Şekil 4 ve Şekil 5'de verilmiştir. Bu eğriler alaşımın sürtünme katsayısının artan yük ve kayma hızı ile azaldığını göstermektedir. Bu sonuçlar alaşımın tribolojik davranışına dayandırılarak açıklanabilir(Alemdag \& Beder, 2014, 2015). Şöyle ki; sürtünme deneylerinden sonra alaşımın sürtünme yüzeyinde sıvanmış bir tabakanın oluştuğu ve bu tabakanın artan yük ve kayma hızı ile daha belirgin hale geldiği gözlenmiştir. EDS analizleri bu tabakanın $\mathrm{Al}, \mathrm{Si}, \mathrm{Zn}$ ve $\mathrm{Cu}$ elementlerinin yanı sıra yüksek oranda oksijen içerdiğini göstermiştir. Bilindiği gibi özellikle çinkonun oksidi hem yağlayıcı olarak davranmakta hem de sıvanmayı kolaylaştırmaktadır (Alemdag \& Beder, 2014, 2015; Prasad et al., 1998; Sarkar, 1975; Sarkar \& Clarke, 1980; Yasmin, Khalid, \& Haque, 2004). Dolayısıyla, sıvama tabakasının artan yük ve kayma hızı ile belirgin hale gelmesi kaymayı kolaylaştırarak sürtünme katsayısının azalmasına yol açmış olabilir.

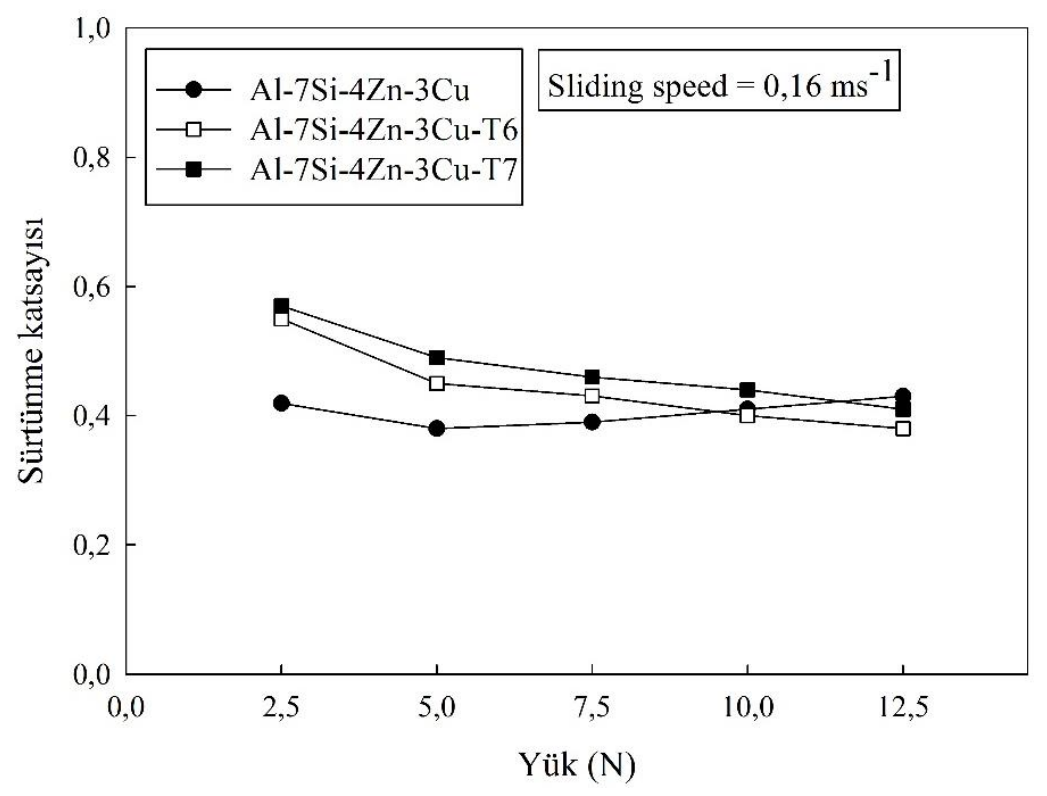

Şekil 4. Alaşımın sürtünme katsayısının uygulanan yük ile değişimini gösteren eğriler. 


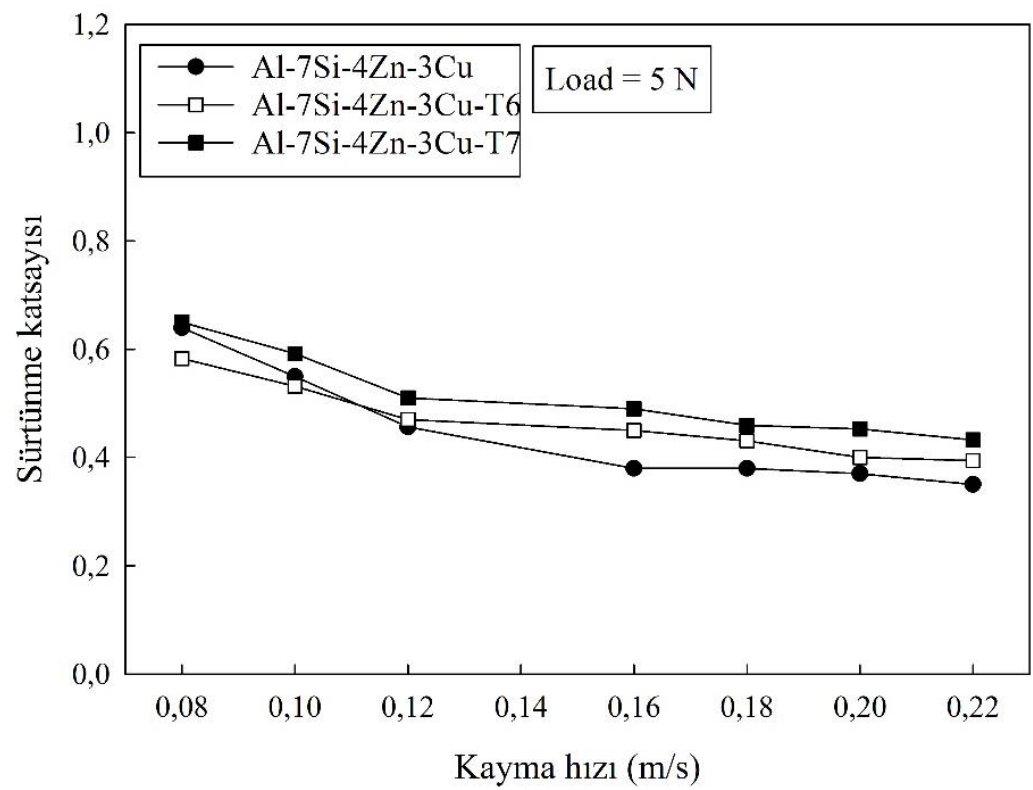

Şekil .5 Alaşımın sürtünme katsayısının kayma hızı ile değişimini gösteren eğriler.

Aşınma deneyleri sonucunda dökülmüş ve 1sıl işlem görmüş durumdaki alaşımda meydana gelen aşınma kaybının uygulanan yüke göre değişimini gösteren eğriler Şekil 6 verilmiştir. Alaşımın aşınma kaybının artan yük ile sürekli arttığı ancak ısıl işlem görmüş durumdaki alaşımın 7,5 N'dan sonraki yüklerde dökülmüş durumundan daha yükssek aşınma direnci sergilediği görülmüştür, Şekil 6. Özellikle T6 1 sıl işleminin hemen hemen tüm koşullarda alaşımın aşınma direncini önemli oranda iyileştirdiği belirlenmiştir. Bu sonuçlar alaşımın mekanik özelliklerine dayandırılarak açıklanabilir. T6 ve T7 isıl işlemlerinden sonra alaşımın akma ve çekme dayanımının arttığı görülmüştür. Bu özeliklerin yanı sıra T6 ısıl işleminden sonra alaşımın sertliğinin de arttığı fakat T7 isıl işleminden sonra ise düştüğü belirlenmiş̧tir. Metallerde meydana gelen aşınma kaybının uygulanan yük ile doğru orantılı olarak arttığı, bunların sertlik ve dayanımları ile ters orantılı olarak azaldığı bilinmektedir. Dolayısıyla ısıl işlemden sonra alaşımın dayanımında meydana gelen artış bunların dökülmüş durumuna göre daha yüksek aşınma direnci sergilemesine yol açmış olabilir. T6 1 sıl işlemi uygulanmış alaşımın T7 uygulanmış durumundakinden daha yüksek aşınma direnci sergilemesi ise bu alaşımın sertliğinin söz konusu işlemden sonra artmasından kaynaklanmış olabilir.

Farklı kayma hızlarında aşınma deneyine tabi tutulmuş dökülmüş ve isıl işlem görmüş durumdaki alaşımda meydana gelen aşınma kaybının kayma hızına göre değişimini gösteren eğriler Şekil 7'de verilmiştir. Şekil 7'deki eğrilerden dökülmüş durumdaki alaşımda meydana gelen aşınma kaybının artan hız ile azalıp $0,16 \mathrm{~ms}^{-1}$ 'lik kayma hızında en düşük değerine ulaştıktan sonra tekrar arttığı, T6 ve T7 ısıl işlemi görmüş durumdaki alaşımın bu değerinin ise dökülmüş durumundakinin tersi bir değişim sergilediği görülmüştür. Bu sonuçlar alaşımın mekanik özelliklerine dayandııılarak açıklanabilir. Şöyle ki; dökülmüş durumdaki alaşımın akma dayanımının düşük olması aşınma sırasında oluşan aşınma parçacıklarının yüzeye sıvanmasını kolaylaştırmış olabilir. Ancak belli bir hız değerinden sonra sürtünme 1sısına bağlı olarak oksitlenme hızının artması, deformasyon sertleşmesi ve yorulma gibi etkiler bu tabakanın yer yer parçalanmasına yol açarak aşınma kaybını arttırmış olabilir. Isıl işlem görmüş durumdaki alaşımlarda ise aşınma parçacıkların yüzeye tekrar sıvanması bunların akma ve çekme dayanımlarının yüksek olması nedeni ile zorlaşabilir. Bu parçacıklar merkezkaç kuvvetinin etkisiyle yüzeyden uzaklaşarak aşınma kaybının artmasına yol açabilir. Ancak belirli bir hız değerinden sonra sürtünme isısında meydana gelen artış T6 ve T7 işlemi uygulanmış alaşımın ana matrisinde bir yumuşamaya yol açarak yüzeyden kopan parçacıkların bir kısmının tekrar yüzeye gömülmesini kolaylaştırabilir. Bu durum söz konu işlemleri görmüş alaşımlarda belirli bir hız değerinden sonra aşınma kaybının azalmasına neden olabilir. 


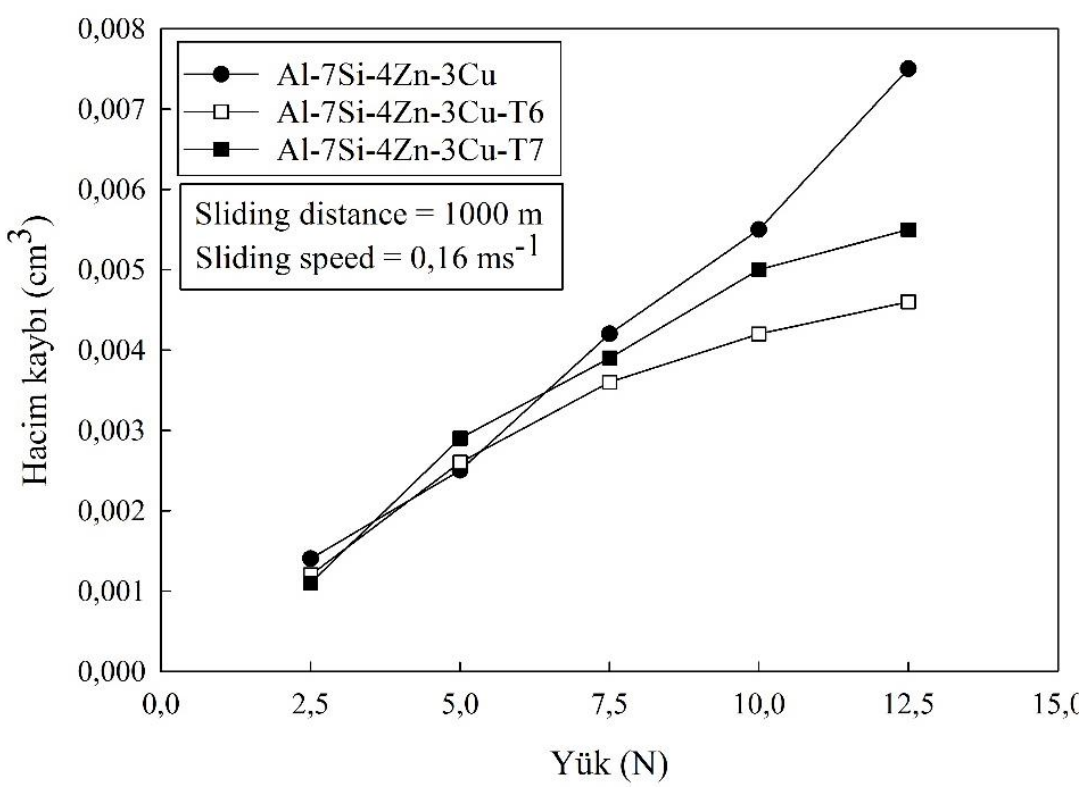

Şekil 6.Alaşımın aşınma kaybının uygulanan yüke göre değişimini gösteren eğriler

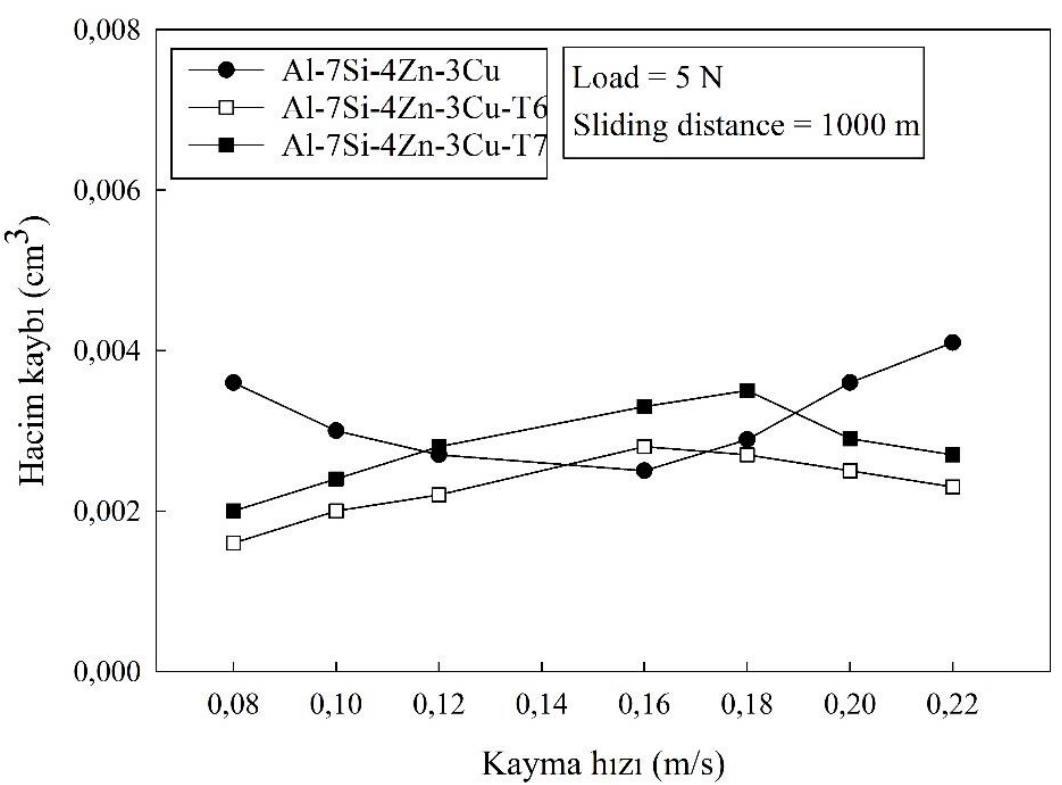

Şekil 7.Alaşımın aşınma kaybının kayma hızına göre değişimini gösteren eğriler

SEM incelemeleri hem dökülmüş hem de 1sıl işlem görmüş durumdaki alaşımın aşınmış yüzeylerinin birbirine oldukça benzer olduğunu göstermiştir. Bu nedenle Şekil 8 ve Şekil 9'da düşük, orta ve yüksek yük ve kayma hızlarında aşınma deneyine tabi tutulan dökülmüş durumdaki $\mathrm{Al}-7 \mathrm{Si}-4 \mathrm{Zn}-3 \mathrm{Cu}$ alaşımının aşınma yüzeyine gösteren fotoğraflar verilmiştir. Buna ek olarak aşınma yüzeylerinin kimyasal bileşimini gösteren EDS analiz sonuçları bu fotoğraflar üzerinde gösterilmiştir. T6 ve T7 1 sıl işlemi görmüş durumdaki alaşımın aşınmış yüzeylerinden de benzer görüntüler ve analiz sonuçları elde edilmiştir. Bu görüntüler incelendiğinde alaşımın aşınmış yüzeylerinde sıvama tabaklarının oluştuğu ve bu tabakada zaman zaman soyulmaların meydana geldiği gözlenmiştir. Sıvanmanın yüzeyden kopan aşınma parçacıklarının numune ile bilye arasında hareket ederken tekrar geriye yapışması sonucunda oluştuğu düşünülmektedir. Ancak oksidayson, deformasyon sertleşmesi ve yorulma gibi etkiler belirli bir kalınlığa ulaşan bu tabakada çatlakların oluşmasına yol açmış olabilir. Bu çatlakların birleşmesi sıvama tabakasının yer yer parçalanmasına dolayısıyla soyularak sürekliliğini kaybetmesine neden olabilir. Diğer taraftan yük ve kayma hızı artıkça sıvanmanın ve soyulmanın daha belirgin olduğu gözlenmiştir. Bu durum söz konusu koşullarda sürtünme ısısının ve oksitlenme hızının artmasından kaynaklanmış olabilir(Prasad et al., 1998; Yasmin et al., 2004). 

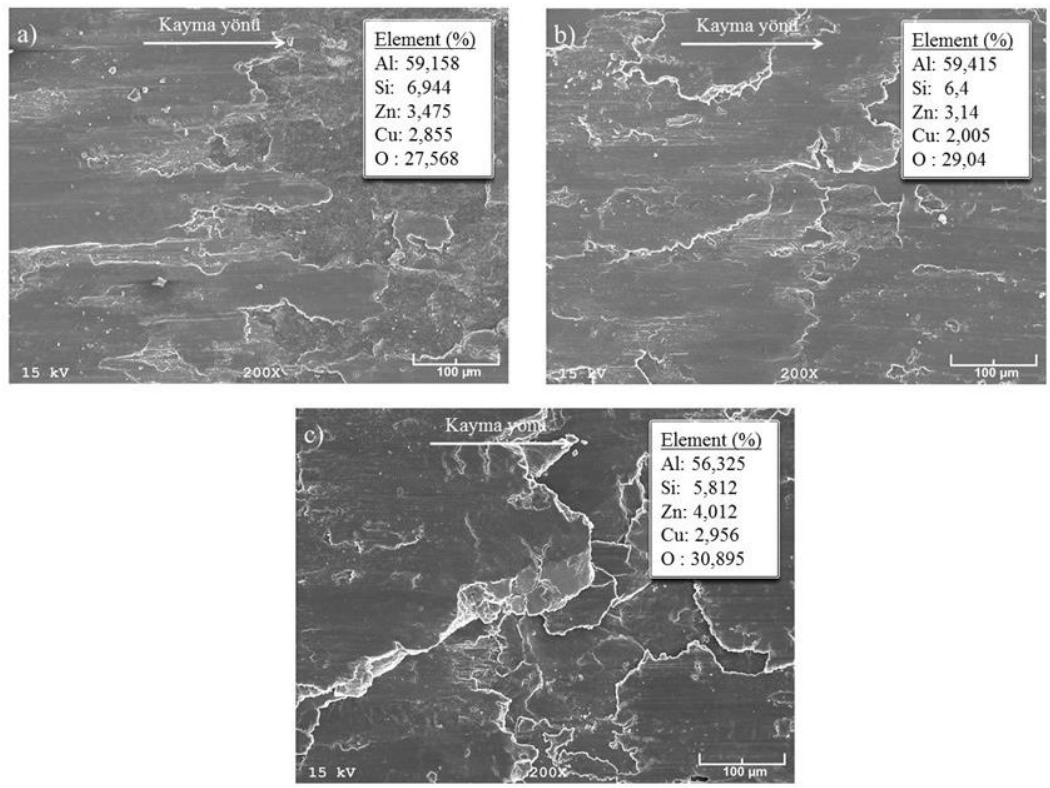

Şekil 8.Farklı yüklerde ((a) 2,5N, (b) 7,5 N ve (c) 12,5 N )aşınma deneyine tabi tutulan dökülmüş durumdaki Al-7Si-4Zn-3Cu alaşımının aşınma yüzeyini gösteren SEM fotoğrafları
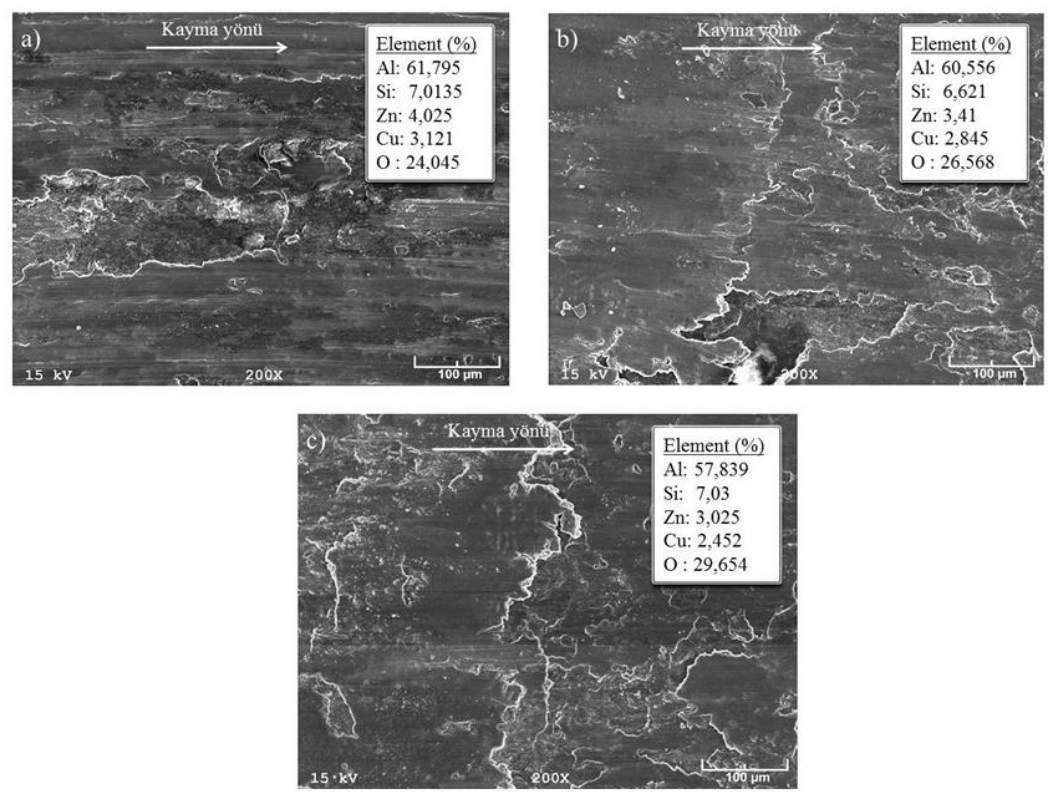

Şekil 9.Farklı kayma hızlarında ((a) $0,08 \mathrm{~m} / \mathrm{s}$, (b) $0,18 \mathrm{~m} / \mathrm{s}$ ve (c) $0,22 \mathrm{~m} / \mathrm{s}$ ) aşınma deneyine tabi tutulan dökülmüş durumdaki $\mathrm{Al}-7 \mathrm{Si}-4 \mathrm{Zn}-3 \mathrm{Cu}$ alaşımının aşınma yüzeylerini gösteren SEM fotoğrafları

\section{Sonuçlar}

$\mathrm{Bu}$ çalışmadan elde edilen ana sonuçlar aşağıda verilmiştir.

a) $\mathrm{Al}-7 \mathrm{Si}-4 \mathrm{Zn}-3 \mathrm{Cu}$ alaşımının içyapısının $\alpha$-Al dendritleri, ötektik ve birincil silisyum parçacıkları ile $\theta$ fazından $\left(\mathrm{CuAl}_{2}\right)$ oluşmaktadır. Çözündürme ve yaşlandırma ısıl işleminden sonra alaşımın dendritik yapısı nispeten ortadan kalkmakta, ancak $\mathrm{Si}$ ve $\theta$ parçacıklarının morfolojisi bu işlemlerden fazla etkilenmemektedir.

b) T6 ve T7 ısıl işlemleri alaşımın akma ve çekme dayanımını artırmaktadır. Diğer taraftan T6 1sıl işlemi alaşımın sertliğini de artırmakta, T7 1 sıl işlemi ise düşürmektedir.

c) Alaşımın hem dökülmüş hem de T6 ve T7 1sıl işlemlerini görmüş durumundaki sürtünme katsayısı artan yük ve kayma hızı ile azalmaktadır.

d) Alaşımın incelenen tüm durumlarındaki aşınma kaybı artan yük ile nispeten doğrusal olarak artmaktadır. Diğer taraftan söz konusu alaşımın 1 sıı işlem görmüş durumlarındaki aşınma kaybı artan kayma hızı ile artmakta, kayma hızının belirli değerlerinden 
$\left(0,16-0,18 \mathrm{~ms}^{-1}\right)$ sonra bir düşüş sergilemektedir. Dökülmüş durumdaki alaşımın aşınma kaybı ise artan kayma hızı ile azalmakta $0,16 \mathrm{~ms}^{-1}$ 'lik kayma hızında en düşük değerine ulaştıktan sonra artmaktadır.

e) T6 ve T7 ısıl işlemleri alaşımın aşınma direncini iyileştirmekte, bu iyileşme artan yük ve kayma hızlarında daha belirgin hale gelmektedir.

f) Hem dökülmüş hem de ısıl işlem görmüş alaşımın aşınmış yüzeylerinde sıvama tabakaları oluşmakta ve soyulmalar meydana gelmektedir. Alaşımın aşınma davranışı, bu iki etkin mekanizma tarafından kontrol edilmektedir.

\section{Teşekkür}

Bu çalışma, Karadeniz Teknik Üniversitesi Bilimsel Araştırma Projeleri Birimi (BAP) tarafından desteklenen 8650 nolu proje kapsamında gerçekleştirilmiştir. Üniversitemiz ve ilgili biriminde görev alan yetkililere teşekkür ederiz.

\section{Referanslar}

Alemdag, Y., \& Beder, M. (2014). Microstructural, mechanical and tribological properties of Al-7Si-(0-5)Zn alloys. Materials \& Design, 63, 159-167. doi:10.1016/j.matdes.2014.06.006

Alemdag, Y., \& Beder, M. (2015). DRY SLIDING WEAR PROPERTIES OF Al-7Si-4Zn-(0-5)Cu ALLOYS. Journal of the Balkan Tribological Association, 21(1), 154-165.

Alemdag, Y., \& Savaskan, T. (2008). Effects of silicon content on the mechanical properties and lubricated wear behaviour of Al40Zn-3Cu-(0-5)Si alloys. Tribology Letters, 29(3), 221-227. doi:10.1007/s11249-008-9299-0

Anasyida, A. S., Daud, A. R., \& Ghazali, M. J. (2010). Dry sliding wear behaviour of Al-12Si-4Mg alloy with cerium addition. Materials \& Design, 31(1), 365-374. doi:10.1016/j.matdes.2009.06.007

Bai, B. N. P., \& Biswas, S. K. (1987). Characterization of Dry Sliding Wear of Al-Si Alloys. Wear, 120(1), 61-74. doi:Doi 10.1016/0043-1648(87)90133-5

Birol, Y. (2008). Semisolid processing of near-eutectic and hypereutectic Al-Si-Cu alloys. Journal of Materials Science, 43(10), 3577-3581. doi:10.1007/s10853-008-2565-6

Chen, C. L., \& Thomson, R. C. (2010). The combined use of EBSD and EDX analyses for the identification of complex intermetallic phases in multicomponent Al-Si piston alloys. Journal of Alloys and Compounds, 490(1-2), 293-300. doi:10.1016/j.jallcom.2009.09.181

Cho, S. J., Hockey, B. J., Lawn, B. R., \& Bennison, S. J. (1989). Grain-Size and R-Curve Effects in the Abrasive Wear of Alumina. Journal of the American Ceramic Society, 72(7), 1249-1252. doi:DOI 10.1111/j.1151-2916.1989.tb09718.x

Clarke, J., \& Sarkar, A. D. (1979). Wear Characteristics of as-Cast Binary Aluminium-Silicon Alloys. Wear, 54(1), 7-16. doi:Doi 10.1016/0043-1648(79)90044-9

Cui, C. S., Schulz, A., Matthaei-Schulz, E., \& Zoch, H. W. (2009). Characterization of silicon phases in spray-formed and extruded hypereutectic Al-Si alloys by image analysis. Journal of Materials Science, 44(18), 4814-4826. doi:10.1007/s10853-009-3734-y

Dwivedi, D. K. (2010). Adhesive wear behaviour of cast aluminium-silicon alloys: Overview. Materials \& Design, 31(5), 25172531. doi:10.1016/j.matdes.2009.11.038

El-Salam, F. A., El-Khalek, A. M. A., Nada, R. H., Wahab, L. A., \& Zahran, H. Y. (2010). Effect of Sn content on the structural and mechanical properties of Al-Si alloy. Materials Science and Engineering a-Structural Materials Properties Microstructure and Processing, 527(4-5), 1223-1229. doi:10.1016/j.msea.2009.10.002

Eshaghi, A., Ghasemi, H. M., \& Rassizadehghani, J. (2011). Effect of heat treatment on microstructure and wear behavior of AlSi alloys with various iron contents. Materials \& Design, 32(3), 1520-1525. doi:10.1016/j.matdes.2010.10.014

Fatahalla, N., Hafiz, M., \& Abdulkhalek, M. (1999). Effect of microstructure on the mechanical properties and fracture of commercial hypoeutectic Al-Si alloy modified with Na, Sb and Sr. Journal of Materials Science, 34(14), 3555-3564. doi:Doi 10.1023/A:1004626425326

Jasim, K. M., \& Dwarakadasa, E. S. (1987). Wear in Al-Si Alloys under Dry Sliding Conditions. Wear, 119(1), 119-130. doi:Doi 10.1016/0043-1648(87)90102-5

Kori, S. A., Murty, B. S., \& Chakraborty, M. (2000). Development of an efficient grain refiner for Al-7Si alloy and its modification with strontium. Materials Science and Engineering a-Structural Materials Properties Microstructure and Processing, 283(1-2), 94-104. doi:Doi 10.1016/S0921-5093(99)00794-7 
Mohamed, A. M. A., Samuel, A. M., Samuel, F. H., \& Doty, H. W. (2009). Influence of additives on the microstructure and tensile properties of near-eutectic Al-10.8\%Si cast alloy. Materials \& Design, 30(10), 3943-3957. doi:10.1016/j.matdes.2009.05.042

Nikanorov, S. P., Volkov, M. P., Gurin, V. N., Burenkova, Y. A., Derkachenko, L. I., Kardashev, B. K., . . Wilcox, W. R. (2005). Structural and mechanical properties of Al-Si alloys obtained by fast cooling of a levitated melt. Materials Science and Engineering a-Structural Materials Properties Microstructure and Processing, 390(1-2), 63-69. doi:10.1016/j.msea.2004.07.037

Nogita, K., Yasuda, H., Yoshiya, M., McDonald, S. D., Uesugid, K., Takeuchi, A., \& Suzuki, Y. (2010). The role of trace element segregation in the eutectic modification of hypoeutectic Al-Si alloys. Journal of Alloys and Compounds, 489(2), 415-420. doi:10.1016/j.jallcom.2009.09.138

Prasad, B. K. (1997). Effects of silicon addition and test parameters on sliding wear characteristics of zinc-based alloy containing 37.5\% aluminium. Materials Transactions Jim, 38(8), 701-706. doi:DOI 10.2320/matertrans1989.38.701

Prasad, B. K., Venkateswarlu, K., Modi, O. P., Jha, A. K., Das, S., Dasgupta, R., \& Yegneswaran, A. H. (1998). Sliding wear behavior of some Al-Si alloys: Role of shape and size of Si particles and test conditions. Metallurgical and Materials Transactions a-Physical Metallurgy and Materials Science, 29(11), 2747-2752. doi:DOI 10.1007/s11661-998-0315-7

Raghavan, V. (2007). Al-Si-Zn (Aluminum-Silicon-Zinc). Journal of Phase Equilibria and Diffusion, $28(2), 197-197$. doi:10.1007/s11669-007-9030-0

Sarkar, A. D. (1975). Wear of Aluminium-Silicon Alloys. Wear, 31(2), 331-343. doi:Doi 10.1016/0043-1648(75)90167-2

Sarkar, A. D., \& Clarke, J. (1980). Friction and Wear of Aluminium-Silicon Alloys. Wear, 61(1), 157-167. doi:Doi 10.1016/00431648(80)90120-9

Savaskan, T., \& Aydiner, A. (2004). Effects of silicon content on the mechanical and tribological properties of monotectoid-based zinc-aluminium-silicon alloys. Wear, 257(3-4), 377-388. doi:10.1016/j.wear.2004.01.007

Savaskan, T., \& Bican, O. (2005). Effects of silicon content on the microstructural features and mechanical and sliding wear properties of Zn-40Al-2Cu-(0-5)Si alloys. Materials Science and Engineering a-Structural Materials Properties Microstructure and Processing, 404(1-2), 259-269. doi:10.1016/j.msea.2005.05.078

Savaskan, T., Hekimoglu, A. P., \& Purcek, G. (2004). Effect of copper content on the mechanical and sliding wear properties of monotectoid-based zinc-aluminium-copper alloys. Tribology International, 37(1), 45-50. doi:10.1016/S0301-679x(03)00113-0

Tiryakioglu, M. (2008). Si particle size and aspect ratio distributions in an Al-7\%Si-0.6\% Mg alloy during solution treatment. Materials Science and Engineering a-Structural Materials Properties Microstructure and Processing, 473(1-2), 1-6. doi:10.1016/j.msea.2007.03.044

Torabian, H., Pathak, J. P., \& Tiwari, S. N. (1994). Wear Characteristics of Al-Si Alloys. Wear, 172(1), 49-58. doi:Doi 10.1016/0043-1648(94)90298-4

Xu, C. L., Yang, Y. F., Wang, H. Y., \& Jiang, Q. C. (2007). Effects of modification and heat-treatment on the abrasive wear behavior of hypereutectic Al-Si alloys. Journal of Materials Science, 42(15), 6331-6338. doi:10.1007/s10853-006-1189-y

Yasmin, T., Khalid, A. A., \& Haque, M. M. (2004). Tribological (wear) properties of aluminum-silicon eutectic base alloy under dry sliding condition. Journal of Materials Processing Technology, 153, 833-838. doi:10.1016/j.jmatprotec.2004.04.147

Ye, H. Z. (2003). An overview of the development of Al-Si-alloy based material for engine applications. Journal of Materials Engineering and Performance, 12(3), 288-297. doi:Doi 10.1361/105994903770343132

Zedan, Y., Samuel, F. H., Samuel, A. M., \& Doty, H. W. (2010). Effects of Fe intermetallics on the machinability of heat-treated Al-(7-11)\% Si alloys. Journal of Materials Processing Technology, 210(2), 245-257. doi:10.1016/j.jmatprotec.2009.09.007 